\title{
Cortázar y la creación de palabras. A propósito de las mancuspias
}

\author{
Luis González García \\ Universidade da Coruña / Grupo Hispania \\ luis.gonzalezg@udc.es \\ http://orcid.org/0000-0003-4335-6528
}

Recibido o 13/10/2017

Aceptado o 02/03/2018

\section{Inventing words: Cortázar's mancuspias}

\section{Resumo}

El objetivo de este trabajo es estudiar una de las creaciones léxicas más conocidas de Julio Cortázar, la palabra mancuspia, que designa a unas misteriosas criaturas fantásticas aparecidas en su cuento "Cefalea" (Bestiario). Para ello, después de encuadrarla en el marco general de creación de nuevas palabras propuesto por Cortázar para la renovación del léxico literario (el conocido glíglico, otras lenguas de creación propia como la fortrán) y de ponerla en relación con otros términos surgidos también de la pluma de Cortázar (como el conocido cronopio y otros de la misma naturaleza) concluimos que hay razones para postular que nos hallamos ante un vocablo procedente del gallego, llegado a Argentina como otras muchas palabras en boca de los emigrantes, al que habría tenido acceso Cortázar de manera indirecta. Para justificar esta aserción ofrecemos la documentación, oral y escrita, de que disponemos en gallego (fuentes lexicográficas y muestras textuales), alguna inédita.

\section{Palabras chave}

Léxico; galleguismos; creación de palabras; Cortázar; mancuspia

\section{Sumario}

1. Cortázar y la renovación de la lengua literaria. 2. Cortázar y la creación de palabras. 3. Cronopios y mancuspias. 4. Mancuspia en gallego. 5. Mancuspia en América. 6. Conclusiones.

\begin{abstract}
This article is a study of one of the best known lexical creations of the author Julio Cortázar: mancuspia, the name given to mysterious creatures that appear in his story "Cefalea" (Bestiario). After situating this term within the general framework of creation of new words proposed by Cortázar for the purpose of renewing the American Spanish literary lexicon (some other examples are cronopio, fortrán and glíglico), it is argued that the word may have a Galician origin, having reached Argentina with immigrants as is the case of many other words; Cortázar would have had indirect access to it. Oral and written documentation, some hitherto unpublished, are presented as proof.
\end{abstract}

Keywords

Lexicology; Galician language; word creation; Cortázar; mancuspia

Contents

1. Cortázar and the renewal of the literary language. 2. Cortázar and the invention of new words. 3. Cronopios and mancuspias. 4. Mancuspia in Galician. 5. Mancuspia in Latin America. 6. Conclusion. 
¿Por qué los críticos tenderán a imaginar en un texto cualquier cosa salvo la imaginación? El joven platense que consultó todos los diccionarios de la Biblioteca Nacional buscando la palabra mancuspia... (Julio Cortázar, Último round: I, 28).

\section{Cortázar y la renovación de la lengua literaria}

Este trabajo es continuación de uno anterior (González, en evaluación). En realidad, cronológicamente esta segunda parte surgió antes de la anteriormente citada, que era una mera introducción. Ahora bien, la preocupación de Cortázar por el lenguaje, por la renovación de la lengua literaria es tal y el material de tipo lingüístico disponible en sus obras tan copioso que dicho capítulo introductorio creció tanto como para convertirse en un trabajo independiente.

Partiendo, pues, de los presupuestos allí enunciados concluimos nuestra aproximación con un acercamiento más concreto, ejemplificado en la palabra mancuspia, especialmente en su génesis.

El propio Cortázar reconoce en diferentes entrevistas y obras de crítica la importancia que concede a la renovación de la lengua literaria: "Pero yo creo que tal vez Rayuela ha tenido una influencia que a mí me alegra — porque era uno de mis deseos - en el lenguaje" (Prego 1985: 104). Cortázar logra, como pocos autores en lengua castellana, alcanzar el propósito que ya en "Teoría del túnel", escrito en 1947, preconizaba:

Los escritores amplían las posibilidades del idioma, lo llevan al límite, buscando siempre una expresión más inmediata, más cercana al hecho en sí que sienten y quieren manifestar, es decir, una expresión no estética, no literaria, no idiomática. EL ESCRITOR ES EL ENEMIGO POTENCIAL —Y HOY YA ACTUAL— DEL IDIOMA. El gramático lo sabe y por eso está siempre vigilante, denunciando tropelías y transgresiones, aterrado ante esa paulatina dislocación de un mecanismo que él concibe, ordena y fija como una perfecta, infalible máquina de enunciación (Cortázar 1947: 77).

Lucha, pues, Cortázar contra lo que él denomina lenguaje literario o lenguaje estético, en el mal sentido de la palabra, que en Rayuela (1963) aparece representado en el capítulo 40 por Lo prohibido de Galdós. Una lengua llena de lugares comunes y léxico selecto. Por contraposición, en la antinovela que propugna Cortázar habrá que empezar por destruir el lenguaje para crear una nueva novela expresada en un nuevo lenguaje. Tarea paradójica pues la lucha contra la palabra se debe realizar con la palabra misma: "Una tentativa de este orden parte de una repulsa de la literatura; repulsa parcial puesto que se apoya en la palabra, pero que debe velar en cada operación que emprendan autor y lector. Así, usar la novela como se usa un revólver para defender la paz, cambiando su signo" (Rayuela: 559-560).

\section{Cortázar y la creación de palabras}

Entre los múltiples procedimientos utilizados por Cortázar para la creación de un nuevo lenguaje literario que no fuese "literario" figuran las creaciones de tipo jitanjafórico. Con este término, tomado de Alfonso Reyes (Arenas 2016), se refiere la crítica literaria a aquellas creaciones léxicas fundamentadas en la inmotivación del signo lingüístico, en la arbitrariedad del significante en términos saussureanos.

En general se trata de palabras encuadradas en la gramática de una lengua (sustantivos, adjetivos, verbos... con su flexión, de ser el caso) pero carentes de existencia fuera de la obra literaria en la que concurren. Por ejemplo, en el siguiente fragmento extraído de 62. Modelo para armar (1968), en la intervención de Polanco, el inseparable compañero de Calac, los tártaros pampeanos, podemos leer:

- Y usted el más petiforro - dice Polanco-. Me llama cronco a mí, pero se ve que nunca se ha huesnado la cara en un espejo (62. Modelo para armar: 56).

En el fragmento se utiliza el verbo huesnar cuyo significado 'mirar' se adivina; se trata de un verbo de la primera conjugación del que en el resto del diálogo se nos ofrece parte del paradigma regular: huesnando, huesnan, huesna, huesnó. En fin, en nada se diferencia este de cualquier otro verbo de la primera conjugación castellana, según el modelo de ahuecar o puentear, salvo en que su uso se limita a una única obra literaria. 
Nos encontramos ante un procedimiento conocido desde antiguo (Eguren 1987) del que la literatura de vanguardia sacó provecho desde sus inicios (en el ámbito hispánico Altazor [1931] de Vicente Huidobro puede ser considerado un hito que influyó grandemente en Cortázar ${ }^{1}$ ). Frente al léxico patrimonial, estas creaciones literarias permiten al autor dar cuenta de múltiples efectos poéticos (connotaciones de distinto tipo como la etnicidad de la poesía negrista, la musicalidad, la parodia de una realidad detestada mediante un léxico absurdo, etc.).

En sus casos más extremos estas creaciones neológicas son totalmente inmotivadas (desde el punto de vista etimológico), pero en otras ocasiones el procedimiento se basa en la deformación reconocible de lexemas existentes en la lengua. Cortázar ofrece abundantes ejemplos de los dos tipos a lo largo de toda su producción:

A este segundo caso de deformación de un léxico preexistente pertenecen, por ejemplo, neologismos como los utilizados por Lonstein en Libro de Manuel (1973) (explicontar, dactilopterodear, se exciforan y se convulrelamen, me incordiumbe), otros muchos documentables en el episodio "La inmiscusión terrupta" de Último round (1969) (precivenir, sujetirar, fraternuliar) o en el glíglico de Rayuela (jadehollante, orgumio), etc.

El primer tipo, formado por creaciones carentes de toda motivación etimológica, está ilustrado con otras voces presentes en las obras anteriores y en otras muchas integradas en el macrotexto narrativo cortazariano, como noema, sustalos, tordular, hurgalios, pínice (Rayuela); crimea, suño, payahás, fitotas en "La inmiscusión terrupta"; cronco, torar, trefulgo, amafar en boca de Calac y Polanco (62. Modelo para armar). También pertenecen a este tipo construcciones aún más desmotivadas como las presentes en los diálogos mantenidos por los personajes de 62. Modelo para armar que la señora de Cinamomo califica como sesiones de infantilismo y se diferencian de las anteriores en que no pueden ser encuadradas en la gramática del español (se trata de palabras oración): bis bis; Guti guti; ptac; honk, honk, honk; ostás fetete; pósenos toque toque sapa (62. Modelo para armar: 63-64).

En realidad, es una constante en la obra de Cortázar el recurso a este tipo de creaciones. En sus principales obras aparecen unos personajes peculiares, de comportamiento impredecible (ajenos al tratamiento psicologicista, previsible, de los personajes decimonónicos), cuyo rechazo del mundo real se manifiesta en la utilización de un léxico diferente del acumulado en el patrimonio de la lengua. El caso más conocido es el glíglico, creado por la Maga, para su comunicación amorosa con Horacio Oliveira (capítulo 68 de Rayuela).

Este recurso fue retomado en 62. Modelo para armar (1968), desarrollo del capítulo 62 de Rayuela, personificado en Calac y Polanco, dos pampeanos cuya lengua es comparada a la de los tártaros, y en Libro de Manuel (1973), uno de cuyos personajes, el rabinito ('judío') cordobés Lonstein, ha creado un lenguaje especial para su comunicación, la fortrán.

Los procedimientos de creación de estos términos en Rayuela y en 62. Modelo para armar son los típicos de este tipo de formaciones ex nihilo propias del lenguaje jitanjafórico. Sin embargo, en Libro de Manuel Lonstein nos ofrece las claves subyacentes a su labor:

-Bueno, nadie pretende que lo sepas, che. Fortrán es un término significante en el lenguaje simbólico del cálculo científico. En otras palabras, formulación transpuesta da fortrán, y eso no lo inventé yo pero encuentro que es una bonita expresión, y por qué entonces no decir boex por bonita expresión, cosa que economiza fonemas, es decir ecofón, no sé si me seguís, en todo caso ecofón tendría que ser una de las bases del fortrán. Con estos métodos sintetizadores, es decir los mesín, se avanza veloz y económicamente hacia la organización lógica de cualquier programa, o sea el orlopró (Libro de Manuel: 1054).

\footnotetext{
'En González García (en evaluación) mostramos la coincidencia de recursos entre ambos autores. En realidad, en estos usos, como en otros muchos, Cortázar recupera el legado de la literatura de vanguardia "que rescata y resucita" (Castro 2016: 139) en su búsqueda de una lengua literaria no estética. Con todo, los lenguajes de base jitanjafórica o con "palabras lúdicas" son muy variados y de origen antiguo. Uno de sus antecedentes más conocidos aparece en el poema Jabberwocky incluido por Lewis Carrol en Alicia a través del espejo (1871). En el ámbito hispánico, Eguren (1987: 38-61) documenta este recurso, además de en las vanguardias, en los antiguos cancioneros, en los clásicos, en la poesía popular, en la tradición oral infantil, etc. Entre los géneros Eguren (1987: 38) resalta "los Ilamados en la jerga teatral 'monstruos', una especie de disparates rítmicos y musicales que se insertaban en las piezas teatrales ligeras a modo de entretenimiento". Entre estas obras cabe citar, por su importancia y por su vinculación con Galicia, la temprana obra de Juan de la Coba (o Xan da Coba), La Trampitana (1895), ópera en un acto, en la que se combinan el trampitán, lengua inventada por el autor, y su traducción en castellano, cuyos musicales primeros versos son los siguientes: "Sus sos au pusus fer pe oselete / tretos ortase laréta zón. / Pengo dofíno la sobenëte / pe to anofo tofo quiquitón." (<http://biblioteca.galiciana.gal/gl/consulta/registro.cmd?id=8005> [Fecha de consulta: 1/02/2018]).
} 
Es decir, buena parte del léxico de Lonstein se basa en la acronimia. Se trata de siglas formadas por la combinación de los fonemas o sílabas iniciales de las expresiones complejas. Pero esta es solo una posibilidad; en la mayoría de los casos las formaciones de Lonstein son aparentemente inmotivadas (apual 'cadáver', ficioro, sundiales, panotear, etc.).

\section{Cronopios y mancuspias}

Estas creaciones desmotivadas morfológicamente se suceden de manera persistente a lo largo de toda la producción de Cortázar. Quizás una de sus creaciones más conocidas sean los cronopios, curiosos personajes que con el tiempo acabarían siendo utilizados por el propio autor y muchos seguidores y amigos como apelativo cariñoso hasta acabar en un proceso de incorporación al léxico común²:

Pero Carlos era bastante más agresivo que yo y decidió mostrarle su indignación no volviendo a dirigirle la palabra en toda la tarde, y hablando en cambio de Paredón, aquel gran cronopio de nuestra izquierda que tanto queríamos y admirábamos ${ }^{3}$.

Efraín [...] era la clase de persona que participaba en la irritante moda del cronopio para hablar de quienes no van al fútbol y quieren vivir en una casa antigua para modernizarla por dentro y llenarla de caballos disecados ${ }^{4}$.

Si bien los cronopios (junto con los famas y los esperanzas) son conocidos principalmente por su aparición en la obra Historias de cronopios y de famas (1962), y también aparecerán en alguna obra posterior (La vuelta al día en ochenta mundos, 1967), lo cierto es que el término se le ocurrió unos diez años antes, como reconoce en algunas cartas escritas al matrimonio Jonquières (Cortázar 2010: 69, 109, 110-111).

Tal como aparecen definidos por Cortázar los cronopios son unos seres verdes y húmedos, desordenados y alegres. Frente a los cronopios, las mancuspias se nos presentan más perturbadoras. Su única aparición se produce en el cuento "Cefalea", integrado en la primera colección de relatos de la que Cortázar estaba suficientemente satisfecho como para prestarle su nombre (Bestiario, 1951). Se trata de unos extraños animales, mamíferos (aunque a sus crías las denomina pichones) que provocan vómitos, dolores de cabeza y otras molestias a sus criadores, en un ambiente inquietante que se anuncia desde el comienzo:

Cuidamos las mancuspias hasta bastante tarde, ahora con el calor del verano se llenan de caprichos y versatilidades, las más atrasadas reclaman alimentación especial y les llevamos avena malteada en grandes fuentes de loza; las mayores están mudando el pelaje del lomo, de manera que es preciso ponerlas aparte, atarles una manta de abrigo y cuidar que no se junten de noche con las mancuspias que duermen en jaulas y reciben alimento cada ocho horas.

No nos sentimos bien. Esto viene desde la mañana, tal vez por el viento caliente que soplaba al amanecer, antes de que naciera este sol alquitranado que dio en la casa todo el día. Nos cuesta atender a los animales enfermos - esto se hace a las once- y revisar las crías después de la siesta. Nos parece cada vez más penoso andar, seguir la rutina (Bestiario. Cuentos Completos: 194-195).

Cortázar señala en varias cartas y entrevistas que el término cronopio carece de toda motivación. Fue una creación espontánea, como señala reiteradamente: a María Rocchi, esposa de Jonquières, en carta fechada el 30 de mayo de 1952 (Cortázar 2010: 69), al traductor de la obra al inglés, Paul Blackburn, en otra de marzo de 1959 (Cortázar 2012), o a su amigo Omar Prego en la larga entrevista que mantuvieron a lo largo de 1983:

Esto pasó poco tiempo después de mi llegada a Francia. Yo estaba una noche en el teatro des Champs Elysées [...] y junto con la aparición de esos objetos verdes, que parecían inflados como globitos o como sapos o algo así, vino la noción de que ésos eran los cronopios. La palabra vino simultáneamente con la visión (Prego 1985: 123).

\footnotetext{
${ }^{2}$ En honor a Cortázar el término se aplicó a un mamífero prehistórico extinto encontrado en Argentina, el cronopio dentiacutus (Rougier / Apesteguía / Gaetano 2011). Del éxito de este término es testigo el académico Diccionario del habla de los argentinos, para cuya tercera edición la Academia Argentina de Letras aprobó en su comisión "Habla de los argentinos" (en sesión del 10 de noviembre de 2016) la inclusión del término cronopio, con las dos acepciones de personaje imaginario cortazariano'y de 'mamífero prehistórico' (http://www.letras.edu.ar/argentinismos10112016.pdf [fecha de consulta: 7/02/2018]). ${ }_{3}^{3}$ Alfredo Bryce Echenique [1981]: La vida exagerada de Martín Romaña (Apud CREA [Fecha de consulta: 20/06/2017]).

${ }^{4}$ Antonio Rodríguez Soria [2012]: José: Fresy Cool (Apud CORPES [Fecha de la consulta: 20/06/2017]).
} 
¿De dónde saqué la palabra cronopio? Vamos, Paul, no deberías preguntar ese tipo de cosas. ¿Cómo puedo saberlo? Yo estaba en el Théatre des Champs Elysées escuchando música y llegaron los cronopios. Simplemente llegaron, en cuerpo y alma [...]. Cronus y opus no significan nada para mí (Cortázar 2012: 181-182, adaptación de los editores).

Por su estructura fonológica (tres o cuatro sílabas, final en diptongo creciente -io, -ia) cronopio sigue el molde de múltiples creaciones cortazarianas (tripolio, orgumio, murelio, ulucordio, persiglotio, exutorio, megacordio, vocifugio, exutorio; nalcunias, contragofia, cariaconcia, tortucomia, etc.). Este patrón se repite en mancuspia, lo que podría hacernos pensar en un origen común jitanjaforico (obsérvese el paralelismo total en el vocalismo entre nalcunias, voz utilizada en "La inmiscusión terrupta", y mancuspias).

Ocurre, sin embargo, que cronológicamente mancuspia es muy anterior a toda esta floración de neologismos idiosincrásicos que culmina en Rayuela con la creación del glíglico. Por otra parte - argumento más sólido- el propio Cortázar reconoce que esta no es una invención suya, como abajo aclararemos.

\section{Mancuspia en Gallego}

La palabra mancuspia es una palabra conocida en gallego. Se la hemos oído por primera vez a nuestro padre (Eliseo González Blanco, nacido en la parroquia de Bendoiro, Lalín, ubicada en la comarca pontevedresa de Deza, en 1922) al relatar un breve cuento popular muy extendido por todo el orbe: tres canteros pasean por la noche cerca de un río, ven la luna reflejada en el agua y piensan que es un queso, de manera que deciden hacer una cadena en la pendiente de la orilla para cogerlo. Cuando ya habían formado la cadena asiéndose de las manos, el que sujeta a los dos compañeros en la parte más alta les dice: "Agarrádevos, que vou facer a mancuspia" ('sujetaos, que voy a escupir en las manos'). Al soltarse, los compañeros caen al río.

De este cuento, Noia Campos (2010: 560-561) bajo el motivo 1250 la cadena humana ( $A$ cadea humana, The Human Chain) $)^{5}$ recoge ocho variantes populares en gallego, además de algunas recreaciones cultas. A ellas podemos añadir una más, inédita, recogida en Pontedeume durante el curso escolar 1988/1989, en la que se justifica el apodo de papadores da Lúa que reciben los habitantes de esa villa coruñesa6:

Miña tía Celsa contábame que un día de lúa chea paseaban catro mariñeiros pola ponte de pedra que vai dende a vila de Cabanas, e viron a lúa no mar, tan clara que lles pareceu un queixo; e como o queixo fresco é a lambetada que máis lles gusta ós de Pontedeume, de seguida puxéronse a miralo e ver a maneira de collelo. O máis listo deles armouna da seguinte forma: el agarrouse no bico da ponte, outro agarrouse ás pernas del, o terceiro baixou por eles e agarrouse no que estaba máis abaixo.

Deste xeito o cuarto comenzou a baixar pola cadea que se formara para coller o queixo coa man. Cando estaba a xeito de o facer o máis listo berroulles: ¡Termádevos ben que vou escupiñar nas mans!

En todas estas versiones se suelen utilizar verbos del tipo cuspir o cuspiñar, equivalentes al castellano escupir, para referirse a la absurda acción que desencadena la caída. Sin embargo, en la versión inédita dezana más arriba mencionada, en lugar del verbo monolexemático se acude a la expresión fraseológica facer a mancuspia. Con ella se alude a la acción que realizan muchos trabajadores consistente en escupir en la palma de la mano antes de sujetar un apero o instrumento y empezar o reanudar su labor.

\footnotetext{
${ }^{5}$ En la versión prototípica del motivo 1250 de la clasificación UTA 2004 (Uther 2004), los tontos intentan medir la profundidad de un pozo o sacar agua de él formando la cadena humana. Escupir en las manos es una constante en este motivo:

1250 The Human Chain (previously Bringing Water from the Well). (Including the previous Type 1250B.) Fools want to measure the depth of a well (retrieve something from the water). They lay a log across its top. One man holds the log with his hands, the next climbs down and holds his feet, and so on. The upper most man becomes tired and lets go to spit in his hands [J2133.5]. All fall in to the well.

In some variants, the human chain is built in order to reach the top of a tree. Cf. Types 121, 1241.In an Indian / Sri Lankan version, the human chain (a chain of monkeys) dangles from the tail of a flying elephant (Uther 2004: 89). ${ }^{6}$ La transcipción pertenece a la alumna de $2^{\circ}$ curso de BUP en el IES de Pontedeume, C. Faraldo, natural de la vecina localidad de Cabana (A Coruña), quien aseguraba haberlo transcrito a partir de una narración de su tía abuela. Agradecemos a Ma Rosario Soto Arias habernos facilitado el texto, que ha permanecido inédito desde esa lejana fecha.
} 
Desde el punto de vista morfológico nos hallamos ante un compuesto transparente formado por los lexemas man 'mano' y cuspir 'escupir'. Se trata de una forma parasintética de la que encontramos escasa documentación en los corpus y diccionarios del gallego. Mayor fecuencia presenta la variante fonética mancospia. Esta variación está provocada por el hecho de que el verbo base, cuspir, pertenece al grupo de los verbos gallegos de la tercera conjugación que presentan alternancia vocálica [0/u] en la flexión de algunos tiempos: cuspo, cospes, cospe, cuspimos...cospen ${ }^{7}$. Así, la forma medieval etimológica cospir (lat. CONSPǓĔRE) acabó regularizada en el moderno cuspir de la misma manera que mancuspia alterna con mancospia [mãn' kospia] en la lengua actual.

Así, pues, mancuspia y mancospia mantienen una variación alomórfica perfectamente regular en gallego. En cuanto al significado, los diccionarios en los que se recoge la entrada según comprobamos en el tesoro lexicográfico del gallego, Dicionario de dicionarios (Santamarina 2003: s. v. mancospia), solo ofrecen valores secundarios para la forma simple mancospia o para la locución facer a mancospia:

1. 'Poca diligencia en el trabajo' (García González 1985: s. v. mancospia); 'hacer que se hace, no trabajar como es debido' (Carré Alvarellos 1951, 1979; Franco Grande 1972: s. v. (facer a) mancospia).

2. 'Reverencia que se hace al entrar en un local donde hay gente' (Rodríguez González 1958-1961, Franco Grande 1972: s. v. mancospia); 'hacer una ligera reverencia de cabeza o del cuerpo, a modo de saludo' (Rodríguez González 1958-1961: s. v. (Facela) mancospia).

La primera acepción es fácilmente justificable a partir de la que arriba hemos apuntado como transparente: escupir en las manos es una preparación para el trabajo pero no implica su realización, por lo que puede quedar en un mero acto de apariencia (conato) ${ }^{8}$. De este valor, puede derivar la segunda acepción figurada.

Estas son, por otra parte, las acepciones que localizamos mayoritariamente en los corpus del gallego ${ }^{9}$. Su frecuencia no es muy alta: se recogen cinco muestras en el Tesouro Informatizado da Lingua Galega (TILG), fechada la más antigua en 1877, y en el Corpus de Referencia del Gallego Actual (CORGA), otras cinco:

1. 'Poca diligencia en el trabajo', 'hacer que se hace, no trabajar como es debido':

Fantasía non lle mancaba ó Xes, e ademáis era traballador de seu, que non facía a mancospia coma algúns que el coñecía... ['Fantasía no le faltaba a Xes, y además era de suyo trabajador, que no hacía como que trabajaba como algunos que él conocía...'] $]^{10}$.

\section{1. 'Reverencia que se hace al entrar en un local':}

Todas tiraron coas rocas sobre da pía do esterco, puxeron ben os refaixos, arrecadaron os pelos, a unha fixeron mancospia e foron entrand'ó medio do corro qu'en pé facíamos no médeo do fiadeiro ['Todas tiraron las ruecas sobre la pila de estiércol, pusieron bien sus refajos, recogieron el pelo, todas a una hicieron una reverencia y fueron entrando en medio del corro que en pie hacíamos en el centro del local donde hilábamos'] ${ }^{11}$.

Sin embargo, si continuamos la búsqueda en el Dicionario de dicionarios y ampliamos el campo de acción a aquellas obras lexicográficas que permanecieron inéditas durante decenios —ajenas a todo el proceso de intertextualidad inherente a cualquier tradición lexicográfica-y solo vieron la luz coincidiendo con su inclusión en este tesoro lexicográfico, el resultado cambia notablemente. En efecto, en el año 2000 publicó García Ares los suplementos que entre 1896 y

\footnotetext{
${ }^{7}$ Las Normas de la Real Academia Galega y el Instituto da Lingua Galega (2012: 127) utilizan como modelo de este paradigma el verbo fuxir, cuya conjugación en presente de indicativo ofrece la siguiente alternancia: fuxo, foxes, foxe, fuximos, fuxides, foxen. Conforme a este modelo se conjugan unas decenas de verbos, algunos de uso frecuente: acudir, bulir (y rebulir), cubrir y derivados, cumprir, durmir, engulir, lucir y derivados, mulir, muxir, pulir, ruxir, sacudir, subir, sufrir, tusir, ulir, urdir, xunguir, xurdir, etc.

${ }^{8}$ Esta acepción es la que persiste en el derivado mancospeiro: 'El que es poco trabajador y hace a mancospia' (Carré 1951, 1979: s. v., Franco Grande 1972: s.v.), 'que non quere traballar ou non traballa como é debido' (Feixó Cid 1986: s. v.).

${ }^{9}$ Existe otra acepción, documentada exclusivamente en un texto del TILG, relacionada con un instrumento de zapatero. Figura, así, en una relación de utensilios de esta profesión que el protagonista del parrafeo desea que el zapatero se vea obligado a comer por su informalidad profesional: "Formas, mancospias e coio / O qu'é mestre d'obra prima, / Engrudo, estribeira, sola, / Chaira, martillo e cuchila, / Cravos, puntas e subelas / Con pinador i estaquillas" (O Tío Marcos da Portela [1877]. Apud TILG [Consultado: 22/05/2017]).

${ }^{10}$ Luis Iglesias de Souza [1989]: As alaudas do mencer (Apud CORGA [Fecha de consulta: 22/05/2017]).

${ }^{11}$ Manuel Lois Vázquez [1890]: Brisas gallegas. Versos (Apud TILG [Consultado: 22/05/2017]).
} 
1902 había ido confeccionando Marcial Valladares como preparación de una segunda edición de su Diccionario castellano-gallego (1884), que nunca llegó a la imprenta. En este suplemento, que como vemos, no pudo servir de fuente para los diccionarios posteriores del gallego, sí encontramos la entrada que nos ocupa, con la variación mancòspia $\sim$ mancúspia $^{12}$, y dos acepciones distintas a las arriba apuntadas, entre ellas la que nos interesa:

Mancòspia: Mancúspia (fague-l-a)

Escupir o salivar en las manos antes de empezar algún trabajo o durante el mismo, como hacen los labradores siempre que la mano les resbala en el mango de la herramienta.

Hacer una higa a alguien u otra acción indecente por el estilo.

Pedín licencia, fíguen a mancòspia,

arrecadèi o pao, tosín primèiro

e lògo comencèi...

M. Curros Enríquez (García Ares 2000: s. v. mancòspia: mancúspia)

Esta segunda acepción ('hacer una higa') no se documenta en ningún otro lugar, lo que hace sospechar acerca de su verosimilitud. La lectura atenta del fragmento utilizado por Valladares para documentarla nos hace discrepar de este autor (usamos la edición de López Varela 1998: I, 847-861). En realidad, la interpretación que nos parece más plausible es la que figura como acepción primera: el poeta decide intervenir en una regueifa cuyo contenido no le satisface: pide permiso, se prepara haciendo que escupe en las manos (como si empezara una labor), agarra el palo que lleva consigo, carraspea y comienza su intervención.

Si nuestra interpretación del texto de Curros es cierta, con esta poseemos dos documentaciones de este significado que denominamos original o transparente, una de ellas nada menos que en la pluma de un autor tan relevante en la historia de la literatura gallega. A ellas debemos añadir una tercera muestra, extraída del TILG (también bajo la forma mancospia como en Curros):

Tamén non está de máis / que algunha vez sintas gana / de te pór tras dun outeiro / inda qu'elí nada fagas /, tendo coidado, ó volver /, de vir recollendo as faldras / da camisa, coma quen / non quer perder tempo, i astra / hai quen faguendo a mancospia / de vez en cando descansa ['Tampoco está de más que alguna vez sientas ganas de ponerte detrás de un otero aunque allí no hagas nada, teniendo cuidado, al volver, de venir recogiendo la falda de la camisa como quien no quiere perder el tiempo, e incluso hay quien descansa de vez en cuando haciendo la mancospia ('deteniéndose a escupir en las manos')'] ${ }^{13}$.

Desde el punto de vista geográfico, no podemos dejar de señalar que todas las muestras que recoge el TILG con los textos más antiguos de la palabra pertenecen a una estrecha área que se extiende desde el curso medio del río Ulla (Boqueixón, A Coruña) hasta Celanova (Ourense), área que atraviesa la comarca pontevedresa de Deza y también las tierras de Maside, de donde era originaria la familia de Aurora Bérnardez, esposa de Córtázar, y donde ella pasó algunos años de su infancia ${ }^{14}$.

Hemos indicado en este apartado que mancuspia y mancospia son formas parasintéticas gallegas en cuya composición entra el verbo cuspir (antiguo cospir). Consideramos que se trata de una forma parasintética porque no hemos hallado una base de derivación verbal sobre la que formar esta unidad, es decir, un verbo compuesto del tipo mancuspir/mancospir sobre el que elaborar una cadena de derivación (man+cuspir>mancuspir>mancuspia, derivado deverbal). Ahora bien, si ampliamos el campo de investigación sobre aquellas otras lenguas peninsulares en las que pervive el verbo cuspir como evolución de consPüĔRE (DCECH: s. v. escupir), frente a aquellas otras que parten del derivado *EXCONSPǓĔRE (como el castellano escupir y el catalán es-

\footnotetext{
${ }^{12}$ Dificulta la localización de esta entrada la acentuación utilizada por Valladares mancòspia y la errata que percibimos en el Dicionario de dicionarios, mancúscpia [sic], por lo que solo cuando estábamos en el proceso de revisión de este trabajo tuvimos acceso a la papeleta realizando la búsqueda mediante comodines: manc?spia.

${ }^{13}$ Xavier Prado [1928]: Cóxegas e moxetes (Apud TILG [Consultado: 22/05/2017]).

${ }^{14}$ En concreto, Valentín Lamas Carvajal (fundador de O tío Marcos da Portela) y Xavier Prado, Lameiro, nacieron en Ourense, en 1849 y 1874, respectivamente; Manuel Lois Vázquez, en Maside (1868); Manuel Curros Enríquez y Celso Emilio Ferreiro, en Celanova (en 1851 y 1912, respectivamente); Anxo Rei Ballesteros, en Boqueixón (1952), en la parroquia de Santaia de Codeso, separada solo por el río Ulla de la de Berres, en A Estrada, de donde era originario el lexicógrafo y erudito Marcial Valladares. Esta continuidad geográfica es un indicio claro del arraigo de la palabra en esta área compacta, aún hoy viva según podemos confirmar con encuestas orales realizadas en la comarca de Deza, donde el valor dominante de la locución es el de 'hacer que se trabaja, no hacer nada', 'ser un vago', incluso, 'hacer el tonto' (facer o parvo).
} 
copir), dicho verbo sí aparece. Además de en portugués, cuspir es la forma documentada en las hablas asturianas y, con ella, el verbo mancuspir, con el significado esperado ${ }^{15}$ :

mancuspir, v. intr. Escupir las manos, frotándolas seguidamente una con otra, antes de tomar un instrumento de trabajo (Sánchez Vicente 1996: s. v.).

mancuspir: v. Cuspir [nes manes] (DLLA: s. v.).

Con todo, el derivado verbal de mancuspir en los bables asturianos no es mancuspia sino el masculino mancuspiu ${ }^{16}$, lo que nos aleja de nuestro objetivo. Lo que sí suscitan estas voces asturianas es la interesante cuestión del denominado léxico occidental, especialmente en lo relativo a los occidentalismos peninsulares en América. Es un hecho bien conocido que en el nivel fonético entre los extremos representados por el gallego y el castellano no existen fronteras rígidas, las isoglosas se van extendiendo gradualmente separando rasgos occidentales y centrales (Martínez Álvarez 1996; Borrego 1996). En el léxico sucede algo semejante. Sin duda como consecuencia de la comunidad que supuso la antigua Gallaecia, el léxico gallego y portugués presenta considerable semejanza con el que globalmente podemos denominar leonés, que se extiende desde Asturias, continuando por la franja occidental de León, Zamora, Salamanca, Extremadura y Andalucía occidental hasta Canarias y, con frecuencia, se prolonga hasta América (Aleza / Enguita 2010: 291). Sólo cuando algún rasgo fonético nos asegure un claro origen gallego o portugués de una voz americana la asignación es segura ${ }^{17}$. En otros muchos casos es necesario un estudio individualizado de cada forma para dilucidar su origen. En esta ocasión los datos nos muestran que la forma mancuspia es exclusiva del gallego, pues ni en portugués, ni en asturiano ni en ningún léxico leonés (Le Men Loyer 2002-2012) se documenta.

\section{Mancuspia en América}

En cuanto al traslado de la palabra a Argentina, la fuerte emigración que desde el último tercio del siglo XIX y la primera mitad del XX partió de Galicia hacia ese nuevo país justifica plenamente la hipótesis de que se trate de un galleguismo ${ }^{18}$.

Los estudios dedicados a esa emigración trasatlántica cifran en unos dos millones el número de gallegos que partieron hacia ultramar entre los siglos XIX y XX (Barreiro 1981: 19-20, Vázquez González 2013: 40), cuyo destino mayoritario fue Argentina (Núñez Seijas 2013: 65), cifra comparable solamente con la de emigrantes italianos. Si se tiene en cuenta el influjo que estos últimos ejercieron en el habla rioplatense (Meo Zilio / Rossi 1970) cabe esperar que aquellos dejasen también su legado en la otra orilla del océano (Gugenberger 2012).

Ahora bien, cuando nos enfrentamos con la tarea de estudiar el poso que toda esa ingente masa de población dejó en el léxico de los países hispanoamericanos nos encontramos prácticamente con el vacío (una inexplicable falta de interés cuyas causas analiza Sinner 2015). Existen trabajos en los que normalmente no se dedican más que unas líneas o párrafos a los occidentalismos en general del español de América (Buesa / Enguita 1992: 200-205; Frago 1999: 60-64; Aleza / Enguita 2002: 248-250, mención especial merece Corominas 1944a, 1944b), alguna obra

\footnotetext{
${ }^{15}$ También Klingebiel (1989: 5) registra el verbo aragonés mancuspir'to spit into one's hands and rub them together before taking hold of a tool'. Sin embargo, la fuente de la que extrae este verbo Klingebiel (1989: 228) nos muestra que se trata de una falsa atribución, pues remite a Novo Mier (1979), un diccionario de la lengua asturiana, por lo que deducimos que la abreviatura arag. que acompaña al verbo a lo largo de toda la obra es una errata por ast.

16 "Mancuspiu, el: sust. Cuspe [que s'echa nes manes]" (DLLA: s.v.); "Mancuspiu, m. Salivazo que se echa en la palma de las manos antes de tomar un instrumento de trabajo y dar comienzo a la labor" (Sánchez Vicente 1996: s. v.); "Mancuspiu (Cbrn. CP.), saliva que se echa de una vez en las manos para asir mejor el mango de un instrumento de trabajo" (Neira / Piñeiro 1989: s.v. escupir).

${ }^{17}$ Como es el caso de la pérdidad de - $/$ - o - $n$ - intervocálicas o el sufijo -iña que se registra en los siguientes términos americanos recogidos en ASALE (2010): Chaira 'navaja' (derivado de chan < lat. PLANUS), esvaído 'mareado, desmayado' (participio de EVANESCĚRE), fariña 'harina gruesa de mandioca o yuca', etc.

${ }^{18}$ Evidentemente, la palabra no llegó a integrarse en el léxico argentino (no figura en los principales diccionarios de americanismos ni de argentinismos que hemos consultado: Segovia 1911, Chuchuy / Hlavacka 1993, Haensch / Werner 2000, Academia Argentina de Letras 2008, ASALE 2010). No deja prácticamente de ser un hápax, pues las abundantes referencias que podemos localizar remiten siempre a la creación cortazariana.
} 
importante dedicada a los lusismos (De Granda 1968; Corbella / Fajardo 2017), pero echamos en falta una centrada exclusivamente en el gallego. Por ello, señala, en un número anterior de esta misma revista, Corbella (2016: 70):

No existe todavía un estudio que analice en su conjunto el aporte léxico patrimonial gallego-portugués al español, tanto europeo como americano. Este hecho se ha atribuido tradicionalmente a la dificultad que entraña la relativa semejanza entre estas lenguas hispánicas y, sobre todo, a la escasez de investigaciones de corte histórico que permitan contrastar con datos objetivos las consecuencias lingüísticas de las interferencias en el tiempo y en el espacio.

En un estudio en preparación (Léxico gallego en el español de América) analizamos una gran cantidad de léxico gallego recogido, sin mencionar su origen, en el Diccionario de Americanismos elaborado por la ASALE (ASALE 2010). Entre estas palabras figuran, a modo de ejemplo, berro 'enojo, enfado', bocoy 'persona baja y muy gorda', bosta 'trabajo mal hecho', botar 'echar', buraco 'herida de bala', cacho 'racimo de bananas', cachola, cachucha 'cabeza', calote 'engaño, cambado 'que tiene una deformidad en las piernas', canga 'traba de madera', cangalla 'traba de madera que se ata al cuello', caruncho'pequeño insecto coleóptero', y otras muchas más. Como prueba del desconocimiento del gallego en los estudios lingüísticos generales baste mencionar el origen inglés ("Del ingl. to bust") que en ese diccionario se asigna a la palabra bostear'excretar el caballo vacuno o caballar' (ASALE 2010: s. v.), galleguismo de antiguo origen céltico demostrado, cuyo radical figura ya en el bronce prerromano de Botorrita (DCECH: s. v. bosta).

El flujo migratorio a Argentina experimentó a finales de los años treinta y principio de los cuarenta la llegada de numerosos intelectuales exiliados tras la Guerra Civil, que se sumaron a la tradicional migración económica. Durante esta época, que coincide con el momento de composición de "Cefalea", Cortázar mantuvo estrechos lazos de amistad con muchos de esos emigrantes gallegos y sus descendientes.

Bestiario fue publicado en 1951 con cuentos compuestos a partir de 1945. Este período comienza con la estancia de Cortázar en la Universidad Nacional de Cuyo (Mendoza) entre 1944 y 1946 y finaliza en Buenos Aires, poco antes de su marcha definitiva a Europa. Algunos de estos cuentos fueron apareciendo, con anterioridad a su publicación en Bestiario, en diferentes revistas entre 1946 y 1948. En concreto, "Casa tomada" fue publicado en 1946 en Los Anales de Buenos Aires, que dirigía Borges, al igual que el relato que da nombre a la colección, "Bestiario" (1947). "Lejana" aparecerá en 1948 en Cabalgata. Mencionamos estas fechas como indicadoras del período de composición de "Cefalea". Los cuentos elaborados con anterioridad, que habían de ser publicados bajo el título de La otra orilla, quedarían inéditos hasta la muerte de Cortázar, con la salvedad de Bruja, que aparecería en 1944 en la revista Correo Literario fundada el año anterior por los exiliados gallegos Arturo Cuadrado, Luis Seoane y Lorenzo Varela. Estos dos últimos serán los directores de la revista Cabalgata donde se publicará por primera vez "Lejana", como acabamos de señalar, y donde Cortázar colabora asiduamente con reseñas literarias entre 1947 y 1948. Los dos primeros fundan también la editorial Nova para la que Cortázar trabajará como traductor desde 1945 y donde estuvo a punto de publicar La otra orilla con ilustraciones de Luis Seoane (si bien el proyecto se aparcaría definitivamente porque Cortázar no estaba plenamente satisfecho de estos cuentos iniciales, al igual que no lo estaba de otras obras redactadas en esta época que solo verían la luz — si antes no fueron destruidas por el propio autor- después de su muerte en 1984).

Los estudios de Fernández Naval (2006) y Salgado (2006) están dedicados en su totalidad a rastrear estas relaciones de amistad entre Cortázar y emigrados gallegos en Buenos Aires. A los tres anteriores cabría añadir a Rafael Dieste (que cederá su piso a Cortázar en 1949, en su estancia en Buenos Aires previa a su marcha definitiva a París) ${ }^{19}$, al editor Francisco Porrúa (nacido en Corcubión, A Coruña), encargado de la edición de Rayuela en la editorial Sudamericana (1963), y, especialmente, a la que sería su esposa (1953-1968), cuidadora en los últimos años de vida y heredera de su obra, Aurora Bernárdez, a la que conocerá en 1948, y a su familia (su madre Dolores Nóvoa y su hermano Francisco Luis Bernárdez, poeta reconocido). Con Aurora, ya esta-

\footnotetext{
${ }^{19}$ En este piso situado en el número 376 de la calle Lavalle escribirá Cortázar la novela El examen (publicada póstumamente) y el ensayo sobre John Keats (Salgado 2006: 22).
} 
blecidos en París, realizó varios viajes a Galicia (1956, 1957), de los que poseemos un material fotográfico cedido por ella junto con todo el fondo fotográfico y fílmico de Cortázar al Centro Galego de Artes da Imaxe (CGAI) en 2005 (en Pérez Touriño et al. 2006 pueden verse algunas de dichas fotografías) ${ }^{20}$.

También pudo haber oído Cortázar la palabra en sus largos paseos por Buenos Aires, en autobús o caminando: pudo oírla en boca de algún emigrante residente en el Río de la Plata. En distintos lugares recuerda que en su juventud solía tomar nota de esas palabras extrañas que oía en sus travesías.

Pero todo esto que estamos mencionando y que justificaría el conocimiento por parte de Cortázar de esta palabra gallega de tan escaso uso no deja de ser quimera en cierto modo porque, como hemos apuntado, la voz no es creación cortazariana.

Cortázar dedica "Cefalea" a un compañero de claustro en la universidad de Cuyo, Ireneo Fernando Cruz, con el que mantuvo una estrecha relación durante el convulsivo período de vida universitaria que le tocó vivir"21: "Asimismo agradecemos a Ireneo Fernando Cruz el habernos iniciado, durante un viaje a San Juan, en el conocimiento de las mancuspias" (Bestiario. Cuentos Completos: 194).

Correas (2014: s. p.) menciona una carta de otro colega y amigo de Cortázar, el musicólogo, poeta y crítico Daniel Devoto, miembro del claustro universitario también y esposo de una hija de Valle-Inclán, Mariquiña, en la cual aclara un poco más la dedicatoria:"Sé — por Julio mismoque la dedicatoria de 'Cefalea' fue en reconocimiento de la propiedad literaria de las protagonistas: Cruz usaba decir 'hace un frío de las mancuspias'". Como señala Herráez (2001: 83) esta expresión ponderativa solo se corresponde nominalmente con los animales ficticios del cuento. Cortázar simplemente aprovechará la eufonía de la palabra, tan semejante a algunas de sus creaciones jitanjafóricas, para denominar a sus animales imaginarios.

Este dato, sin embargo, no soluciona el problema sino que lo traslada. Ireneo Cruz era bonaerense, aunque llevaba ejerciendo distintos puestos en la universidad, de reciente creación, desde 1940. Todo lo que hemos dicho, pues, a propósito de Cortázar y su contacto con emigrantes gallegos, omnipresentes en el Buenos Aires de la época, es válido para Cruz. Es más, en este nuevo contexto de uso ("hace un frío de las mancuspias") la palabra cobra un nuevo vínculo con el viejo término patrimonial en Galicia: cuando hace mucho frío la tendencia natural es la de frotarse las manos al igual que el trabajador que, después de escupir en ellas, se prepara para manejar un apero. Estaríamos, por tanto, ante una evolución de la frase en Argentina divergente pero coherente con la que vimos en Galicia a propósito de mancuspia: ambas se basan en el acto de frotarse las manos, en un caso como paso previo ostensible a la realización de una tarea (que luego puede no llevarse a cabo), en el otro como indicio de frío intenso ${ }^{22}$. Esta vinculación semántica sería un argumento más en favor del origen gallego del término que Cortázar universalizaría.

\footnotetext{
${ }^{20}$ Fruto de este contacto, en el Cuaderno de Bitácora de Rayuela, que el escritor regaló a Ana María Barrenechea, aparece la denominación gallega del juego: “Mariola (Galicia y Coruña)” (Cortázar / Barrenechea 1983/2004: 1293).

${ }^{21}$ La relación entre Cortázar y Cruz (1903-1951) puede rastrearse en Correas (2014). Ireneo Cruz, vinculado al peronismo tras la marcha de Cortázar, sería rector entre 1948 y 1954. Pocos meses después de dejar el cargo fallecería en Mendoza el 3 de junio de 1954, a los 51 años.

22 En un blog del poeta y editor mexicano Víctor Cabrera (Asuntos domésticos <http://asuntosdomesticos.blogspot.com. es/2007/11/> [Fecha de consulta 28/01/2014]) se alude a la existencia de un libro que su amigo uruguayo Gabriel Schutz le había entregado. El libro en cuestión, escrito por su tío abuelo Aníbal Schutz, Leyendas verdaderas de la Pampa, Giuseppe Lampa Editor, Montevideo, 1945, incluía la primera mención de las mancuspias, que sería la fuente usada por Cortázar para su cuento. Veamos un fragmento de este libro ficticio, como nos corroboró el propio Gabriel Schutz, al cual agradecemos este dato:

Originarias de ciertas zonas de Suramérica, las mancuspias son —como las sirenas, la esfinge y el centauro—-seres de naturaleza híbrida que — también a semejanza del ornitorrinco- comparten características de diferentes especies animales. Si bien está documentado que se trata de mamíferos, las crías pequeñas tienen apariencia de pichones y, como ciertos saurios, son capaces de desarrollar un trepar reptante por los postes de los corrales en los que, comúnmente, se les cría en cautiverio. [...]

Una leyenda de la Pampa ha divulgado el rumor infundado de que las mancuspias provocan padecimientos extraños - cefaleas, por ejemplo— tanto en los seres humanos encargados de su crianza como en aquellos que habitan cerca de sus moradas.
} 


\section{Conclusiones}

En este trabajo hemos presentado abundante material sobre el término mancuspia (y su variante mancospia) en gallego, tanto oral como escrito. Hemos documentado, igualmente, las acepciones recogidas en nuestra tradición lexicográfica y también otras palabras emparentadas en los bables asturianos.

Contrastados estos empleos con el uso que Julio Cortázar hace de la voz en "Cefalea" y la fuente de donde, según su propia confesión, extrajo la palabra en un contexto fraseológico (Ireneo Fernando Cruz), concluimos que se puede establecer una relación de evolución semántica entre las acepciones recogidas a ambos lados del Atlántico: la 'acción de frotarse las manos después de escupir en ellas para sujetar un instrumento' (facer a mancuspia) y la 'acción de frotarse las manos para mitigar el frío intenso' (hace un frío de las mancuspias).

A falta de más documentación, hemos formulado la hipótesis de que la llegada de este galleguismo a Argentina se sustenta en la intensa emigración producida desde mediados del siglo XIX hacia América como factor determinante en la difusión en la otra orilla del Atlántico de la voz, cuyo uso debió de ser muy limitado pero suficiente como para llegar a conocimiento de Cortázar y, así, convertirse en uno de los símbolos de su universo literario.

\section{Referencias BIBLIOGRÁFICAS}

Academia Argentina de Letras (2008): Diccionario del habla de los argentinos. Buenos Aires. Editorial Emecé.

Aleza Izquierdo, Milagros / José María Enguita (2002). El español de América aproximación sincrónica. Valencia: Tirant lo Blach.

Aleza Izquierdo, Milagros / José María Enguita Utrilla (coords.) (2010): La lengua española en América: normas y usos actuales. Valencia: Universitat de València.

Arenas Monreal, Rogelio (2016): "Alfonso Reyes y Julio Cortázar: el género de las jitanjáforas, un guiño alfonsino en Rayuela", en Leonardo Funes (coord.), Hispanismos del mundo: diálogos y debates en (y desde) el Sur. Sección VI, Literatura Latinoamericana (ed. de Patricio Fontana). Buenos Aires: Miño y Dávila, 15-23. http://www.uba.ar/ aihbuenosaires2013/ [16/10/2017].

ASALE = Asociación de Academias de la Lengua Española (2010): Diccionario de Americanismos. Madrid: Santillana.

Barreiro Fernández (1981): Historia de Galicia, vol. IV. Vigo: Galaxia.

Borrego Nieto, Julio (1996): "Leonés", en Manuel Alvar (dir.), Manual de dialectología hispánica. El español de España. Barcelona: Ariel, 138-158.

Buesa, Tomás / José Ma Enguita (1992): Léxico del español de América. Madrid: Ed. MAPFRE.

Carré Alvarellos, Leandro (1951): Diccionario galego-castelán. A Coruña: Roel.
Carré Alvarellos, Leandro (1979): Diccionario galego-castelán e Vocabulario castelán-galego. A Coruña: Moret.

Castro, Juan Cristóbal (2016): Idiomas espectrales. Lenguas imaginarias en la literatura latinoamericana. Bogotá: Editorial Pontificia Universidad Javierana.

Chuchuy, Claudio / Laura Hlavacka (1993): Nuevo diccionario de argentinismos. Bogotá: Instituto Caro y Cuervo.

Coba, Juan de la (1895): La Trampitana. Ópera en un acto. Ourense: Imprenta de coplas. Versión digital disponible en http://biblioteca.galiciana.gal/ $\mathrm{gl} /$ consulta/registro.cmd?id=8005.

Corbella, Dolores (2016): "Presencia del léxico gallego-portugués en el español atlántico: primeros testimonios", Estudos de Lingüística Galega 8, 69-87. http://dx.doi.org/10.15304/elg.8.3037.

Corbella, Dolores / Alejandro Fajardo (eds.) (2017): Español y portugués en contacto: Préstamos léxicos e interferencias. Berlin / Boston: Walter de Gruyter.

CORGA = Centro Ramón Piñeiro para a Investigación en Humanidades: Corpus de Referencia do Galego Actual. http://corpus.cirp.es/corga.

Corominas, Juan (1944a): "Indianorománica. Occidentalismos americanos", Revista de Filología Hispánica VI/2, 139-175.

Corominas, Juan (1944b): "Indianorománica (continuación)", Revista de Filología Hispánica Vl/3, 209-254. 
CORPES = Real Academia Española: Corpus del Español del Siglo XXI. http://www.rae.es.

Correas, Jaime (2014): Cortázar en Mendoza. Buenos Aires: Alfaguara. Edición electrónica.

Cortázar, Julio (1947/2006): “Teoría del túnel. Notas para una ubicación del surrealismo y existencialismo", en Obra crítica. Edición de Saúl Yurkievich con la colaboración de Gladis Anchieri. Barcelona: Galaxia Gutemberg / Círculo de Lectores, 45-125.

Cortázar, Julio (1951/2003): Bestiario. Buenos Aires, 1951; en Cuentos completos. Edición de Saúl Yurkievich con la colaboración de Gladis Anchieri. Barcelona: Galaxia Gutemberg / Círculo de Lectores, 159-247.

Cortázar, Julio (1962): Historias de cronopios y de famas. Buenos Aires: Minotauro.

Cortázar, Julio (1963/2005): Rayuela. Buenos Aires, 1963; Ed. de Andrés Amorós. Madrid: Cátedra, 2005.

Cortázar, Julio (1967): La vuelta al día en ochenta mundos. México: Siglo XXI.

Cortázar, Julio (1968/1979): 62. Modelo para armar. Buenos Aires, 1968; Barcelona: EDHASA, 1979.

Cortázar, Julio (1969/2004): Último round. México, 1969; México: Siglo XXI de editores, 2004.

Cortázar, Julio (1973/2004): Libro de Manuel. Buenos Aires, 1973; en Novelas II. Edición de Saúl Yurkievich con la colaboración de Gladis Anchieri. Barcelona: Galaxia Gutemberg / Círculo de Lectores, 865-1234.

Cortázar, Julio (2010): Cartas a los Jonquières. Edición de Aurora Bernárdez y Carles Álvarez Garriga. Barcelona: Alfaguara.

Cortázar, Julio (2012): Cartas. 1955-1964. Edición de Aurora Bernárdez y Carles Álvarez Garriga. Buenos Aires: Alfaguara.

Cortázar, Julio / Ana Ma Barrenechea (1983/2004): Cuaderno de bitácora de Rayuela. Buenos Aires, 1983; en Novelas II. Edición de Saúl Yurkievich con la colaboración de Gladis Anchieri. Barcelona: Galaxia Gutemberg / Círculo de Lectores, 1238-1297.

CREA = Real Academia Española: Corpus de referencia del español actual. http://www.rae.es.

DCECH = Coromines, Joan / José Antonio Pascual (1980-1991): Diccionario crítico etimológico castellano e hispánico, 5 vols. Madrid: Gredos.
De Granda, Germán (1968): "Acerca de los portuguesismos en el español de América", Thesaurus. Boletín del Instituto Caro y Cuervo 23, 344-358.

DLLA = Academia de la Llingua Asturiana (2000): Diccionariu de la llingua asturiana. Uviéu: Academia de la Llingua Asturiana.

Eguren Gutiérrrez, Luis J. (1987): Aspectos lúdicos del lenguaje. La jitanjáfora, problema lingüístico. VaIladolid: Universidad de Valladolid.

Feixó Cid, Xosé G. (coord.) (1986): Diccionario da lingua galega. Vigo: Ir Indo.

Fernández Naval, Francisco X. (2006): Respirar polo idioma (Os galegos e Julio Cortázar). Ourense: Linteo.

Frago Gracia, Juan Antonio (1999): Historia del español de América. Madrid: Gredos.

Franco Grande, Xosé Luís (1972): Diccionario galego-castelán. Galaxia: Vigo.

García Ares, Maricarme (ed.) (2000): Nuevo suplemento al diccionario gallego-castellano publicado en 1884 por Dn. M(arcial) V(alladares) N(úñez). A Coruña: Real Academia Galega (Anexo 4 de Cadernos de Lingua).

García González, Constantino (1985): Glosario de voces galegas de hoxe. Santiago de Compostela: Universidade de Santiago (Anexo 27 de Verba).

González García, Luis (en evaluación): “Cortázar y la formación de palabras".

González García, Luis (en preparación): Léxico gallego en el español de América.

Gugenberger, Eva (2012): “¿Existe un 'cocoliche gallego'? La inmigración gallega y sus implicaciones lingüísticas", en Ángela Di Tullio / Rolf Kailuweit (eds.), El español rioplatense: lengua, literatura, expresiones culturales. Madrid: Iberoamericana / Vervuert.

Haensch, Günther / Reinholds Werner (2000): Diccionario del español de Argentina. Madrid : Gredos.

Huidobro, Vicente (1931/1981): Altazor. Madrid, 1931, ed. René de Costa; Madrid: Cátedra, 1981.

Herráez, Miguel (2001): Julio Cortázar. El otro lado de las cosas. Valencia: Institució Alfons el Magnànim.

Klingebiel, Kathryn (1989): Noun + Verb Compounding in Western Romance. Berkeley / Los Angeles: University of California Press. 
Le Men Loyer, Jeannick (2002-2012): Léxico del leonés actual, 6 vols. León: Centro de Estudios e Investigación San Isidoro.

López Varela, Elisardo (1998): A poesía galega de Manuel Curros Enríquez, 2 vols. A Coruña: Deputación provincial.

Martínez Álvarez, Josefina (1996): "Las hablas asturianas", en Manuel Alvar (dir.), Manual de dialectología hispánica. El español de España. Barcelona: Ariel, 119-133.

Meo Zilio, Giovanni / Ettore Rossi (1970): El elemento italiano en el habla de Buenos Aires y Montevideo. Firenze: Valmartina Editore.

Neira Martínez, Jesús / Ma Rosario Piñeiro (1989): Diccionario de los Bables de Asturias. Oviedo: Instituto de Estudios Asturianos.

Noia Campos, María Camiño (2010): Catálogo tipolóxico do conto galego de tradición oral. Clasificación, antoloxía e bibliografía. Vigo: Universidade.

Novo Mier, Lorenzo (1979): Dicionariu xeneral de la Ilingua asturiana. Oviedo: Asturlibros.

Núñez Seixas, Xosé M. (2013): “A inmigración galega na Arxentina", en Pilar Cagiao Vila (coord.), $A$ emigración galega a América do Sur. A Coruña: Hércules de Ediciones, 65-144.

Pérez Touriño, Emilio et al. (2006): Julio Cortázar / Aurora Bernárdez: Un (re)encuentro con Galicia. Santiago de Compostela: Xunta de Galicia.

Prego, Omar (1985): La fascinación de las palabras. Conversaciones con Julio Cortázar. Barcelona: Muchnik.

Real Academia Galega / Instituto da Lingua Galega (2012): Normas ortográficas e morfolóxicas do idioma galego. Vigo: Galaxia.

Rodríguez González, Eladio (1958-1961): Diccionario enciclopédico gallego-castellano. Galaxia: Vigo.
Rougier, Guillermo / Sebastián Apesteguía / Leandro Gaetano (2011): "Highly specialized mammalian skulls from the Late Cretaceous of South America", Nature 479, 98-102. http://dx. doi.org/10.1038/nature10591

Salgado, Fernando (2006): "Un escritor destetado entre exiliados galegos", en Emilio Pérez Touriño et al., Julio Cortázar/Aurora Bernárdez: Un (re) encuentro con Galicia. Santiago de Compostela: Xunta de Galicia, 13-31.

Sánchez Vicente, Xuan Xosé (1996): Diccionariu asturianu-castellanu, castellanu-asturianu. Uviéu: Trabe.

Santamarina, Antón (2003): Dicionario de dicionarios. A Coruña: Fundación Pedro Barrié de la Maza-Instituto da Lingua Galega. Versión electrónica actualizada disponible en http://sli.uvigo. es/ddd/index.html.

Segovia, Lisandro (1911): Diccionario de argentinismos. Buenos Aires: Imprenta de Coni Hermanos.

Sinner, Carsten (2015): "O galego como lingua de contacto co castelán riopratense: unha relación esquecida", Estudos de Lingüística Galega 8, 187-204. http://dx.doi.org/10.15304/elg.8.2638

TILG = Santamarina, Antón (coord.): Tesouro informatizado da lingua galega. Santiago de Compostela: Instituto da Lingua Galega. http://ilg. usc.es/TILG/.

Uther, Hans-Jörg (2004): The types of international folktales. A classification and bibliography. Part II. Tales of the stupid ogre, anecdotes and jokes and formula tales. Helsinki: Suomalainen Tiedeakatemia.

Vázquez González, Alexandre (2013): "As vagas da emigración galega a Sudamérica", en Pilar Cagiao Vila (coord.), A emigración galega a América do Sur. A Coruña: Hércules de Ediciones, 37-63. 
